\title{
Tephrosia (Leguminosae) no estado do Ceará, Nordeste do Brasil
}

\author{
Tephrosia (Leguminosae) in the state of Ceará, Northeast of Brazil
}

\author{
Rayane de Tasso Moreira Ribeiro ${ }^{1,4}$, Rubens Teixeira de Queiroz $^{2}$ \& Maria Iracema Bezerra Loiola ${ }^{3}$
}

\begin{abstract}
Resumo
Este estudo realizou um levantamento florístico dos representantes de Tephrosia no estado do Ceará, como parte do projeto "Flora do Ceará". O estudo foi baseado na análise comparativa dos caracteres morfológicos de espécimes depositados nos herbários EAC, ESA, HUEFS, IPA, MBM, MOSS, TEPB e UFRN, bibliografias especializadas, fotos de materiais-tipo, além de coletas e observações de campo. Para o estado foram registradas cinco espécies de Tephrosia: T. cinerea, T. domingensis, T. egregia, T. purpurea e T. sinapou. As espécies ocorrem preferencialmente próximo ao litoral, em solos arenosos e antropizados, como floresta estacional semidecidual das terras baixas (tabuleiro costeiro) e vegetação com influência marinha (restinga), com exceção de $T$. domingensis encontrada nos topos serranos em floresta ombrófila densa (mata úmida). Tephrosia sinapou é nova ocorrência para o Ceará. As espécies, em sua maioria, apresentam ampla distribuição e ocorrem em quatro unidades de conservação no Ceará. Palavras-chave: conservação, distribuição, Leguminosae, Millettieae, tabuleiro costeiro.
\end{abstract}

\begin{abstract}
This study presents a floristic survey of Tephrosia occurring in the Ceará state, as part of "Flora of Ceará" project. The study was based on the comparative analysis of morphological characters of specimens deposited in herbaria EAC, ESA, HUEFS, IPA, MBM, MOSS, TEPB and UFRN, bibliography, photo-type material, along with collections and field observations. Five species of Tephrosia were recorded in the state: T. cinerea, T. domingensis, T. egregia, T. purpurea e T. sinapou. The species occur preferentially near the coast, in sandy and antropic soils, like seasonal semideciduous forest of the lowlands (coastal board) and vegetation with marine influence (restinga), with the exception of $T$. domingensis founded in mountain tops in ombrofilous dense forest (wet forest). Tephrosia sinapou is a new record for Ceará state. Most species are widely distributed and occur in four natural reserves in Ceará.
\end{abstract}

Key words: conservation, distribution, Leguminosae, Millettieae, coastal board.

\section{Introdução}

Tephrosia Pers. compreende cerca de 350 espécies, destacando-se por ser um dos maiores gêneros de Fabaceae e amplamente distribuído em todo o mundo (Geesink 1984; Schrire 2005). Seus representantes possuem hábito arbustivo, subarbustivo ou herbáceo, folhas imparipinadas ou unifolioladas, raramente digitadas, inflorescências terminais, axilares ou opostas às folhas, em racemos ou pseudoracemos, cálice campanulado, fruto do tipo legume com cálice persistente (Bosman \& Haas 1983; Queiroz 2012).
O gênero foi estabelecido por Persoon (1807), tendo como espécie tipo T. villosa (L.) Pers. Tephrosia constitui um grupo com histórico taxonômico complexo. Os primeiros trabalhos que trataram a taxonomia de Tephrosia foram os de De Candolle (1825), que propôs a primeira classificação infragenérica reconhecendo quatro seções: Tephrosia sect. Mundulea DC., T. sect. Craccoides DC., T. sect. Brissonia (Necker ex Desv) DC. e T. sect. Reineria DC. Bentham (1862) estabeleceu T. sect. Recueria Benth. e manteve as seções Brissonia e Reineria proposta por De

\footnotetext{
${ }^{1}$ Universidade Federal Rural de Pernambuco, Depto. Biologia, Programa de Pós-graduação em Botânica, Dois Irmãos, 52171-900, Recife, PE, Brasil.

${ }^{2}$ Universidade Federal da Paraíba, Depto. Sistemática e Ecologia, 58051-900, João Pessoa, Paraíba, Brasil.

${ }^{3}$ Universidade Federal do Ceará, Depto. Biologia, Herbário Prisco Bezerra - EAC, bl. 906, Campus do Pici Prof. Prisco Bezerra, 60440-900, Fortaleza, CE, Brasil.

${ }^{4}$ Autora para correspondência: rayanetasso@gmail.com
} 
Candolle em 1825. Já Baker (1871, 1876) manteve o mesmo tratamento proposto por Bentham (1862).

A classificação e o conceito atual do gênero foram propostos por Brummitt (1980) que dividiu Tephrosia em dois subgêneros, $T$. subg. Tephrosia representado por espécies com estilete glabro e $T$. subg. Barbistyla, abrangendo as espécies com estilete pubescente.

Análises filogenéticas recentes baseadas em sequências de ITS e 5.8S rRNA concluíram que as espécies de Tephrosia da África, América do Norte e Ásia constituem um grupo monofilético, além de apresentarem afinidade com os gêneros Requienia DC., Ptycholobium Harms, Caulocarpus E. G. Baker e Lupinophyllum Hutch (Hu et al. 2002).

Os representantes de Tephrosia do Velho Mundo, Oceania, Américas Central e do Norte foram alvo da maior parte dos estudos taxonômicos e florísticos, destacando-se os trabalhos de Bentham (1864), Gillett (1958) e Schrire (1987), além das revisões de Robinson (1899) e Wood (1949) com espécies da América do Norte e Bosman \& Haas (1983) com representantes da Malásia.

Estudos taxonômicos do gênero Tephrosia no Brasil estão limitados aos desenvolvidos para as espécies ocorrentes na América do Sul (Queiroz 2012), e Floresta Atlântica dos estados do Rio Grande do Norte (São-Mateus et al. 2013) e São Paulo (Queiroz et al. 2016), respectivamente.

No Brasil são registradas 12 espécies de Tephrosia, das quais três são endêmicas (Tephrosia adunca Benth., T. egregia Sandwith e T. noctiflora Bojer ex Baker). Os representantes do gênero podem ser encontrados em diferentes domínios fitogeográficos do país, como a Amazônia, Caatinga, Cerrado, Mata Atlântica e Pantanal (Queiroz 2017.

Para o estado do Ceará nenhum estudo taxonômico ou sobre distribuição dos representantes de Tephrosia foi realizado. Inserido no projeto "Flora do Ceará", o presente estudo tem como objetivo o levantamento florístico das espécies de Tephrosia, contribuindo para um maior conhecimento e atualização da distribuição geográfica dos representantes deste gênero.

\section{Material e Métodos}

O estudo baseou-se na análise comparativa de espécimes depositados nos herbários EAC, ESA, HUEFS, IPA, MBM, MOSS, TEPB e UFRN, cujas siglas estão de acordo com Thiers (2016). As identificações foram realizadas com o auxílio de bibliografia especializada e análise de imagens de coleções-tipo disponíveis no sítio dos herbários $\mathrm{B}, \mathrm{BM}, \mathrm{K}, \mathrm{P}$ e TL. Os nomes dos autores foram baseados no sítio IPNI (2016).

A terminologia empregada para as estruturas vegetativas e reprodutivas seguiu Radford et al. (1974); para tipo de indumento e padrão de venação Hickey (1973) e Lawrence (1951). Os dados referentes ao hábito, habitat, período de floração e frutificação e nomes populares foram obtidos dos rótulos das exsicatas. Ressalta-se que a descrição do gênero foi realizada com base apenas nos representantes de Tephrosia ocorrentes no estado do Ceará.

Com relação à distribuição, as espécies foram classificadas em: restritas, quando ocorrem em um a cinco municípios; moderadas, entre cinco e 10 e amplas, encontradas em mais de 10 municípios. Adotou-se, ainda, o sistema de quadrículas, com grade de meio grau (Fig. 1; Menezes et al. 2013).

A classificação da vegetação baseou-se no Manual Técnico da Vegetação Brasileira (IBGE 2012): savana (cerrado), savana estépica (caatinga/ carrasco), floresta estacional decidual (mata seca), floresta ombrófila densa (mata úmida), floresta estacional semidecidual de terras baixas (tabuleiros costeiros) e vegetação com influência marinha (restinga).

\section{Resultados e Discussão}

Para o Ceará foram registradas cinco espécies de Tephrosia: T. cinerea (L.) Pers., T. domingensis (Willd.) Pers., T. egregia Sandwith, T. purpurea (L.) Pers. e T. sinapou (Buc'hoz) A. Chev., sendo esta última, uma nova ocorrência para o estado.

Quanto à distribuição das espécies de Tephrosia registradas no Ceará, quatro ocorrem em toda a América do Sul, enquanto T. egregia é endêmica do Brasil (BFG 2015; Queiroz 2017).

No estado do Ceará, os representantes de Tephrosia habitam preferencialmente ambientes de climas mais secos, solos arenosos e antropizados, como floresta estacional semidecidual de terras baixas (tabuleiros costeiros) e vegetação com influência marinha (restinga), com exceção de $T$. domingensis e $T$. sinapou encontrada em floresta ombrófila densa (mata úmida).

Em território cearense, três espécies de Tephrosia apresentaram distribuição moderada a ampla e foram encontradas em unidades de conservação do estado, são elas: $T$. cinerea, $T$. egregia e $T$. purpurea. Isto demonstra a necessidade de estudos com ênfase na avaliação 


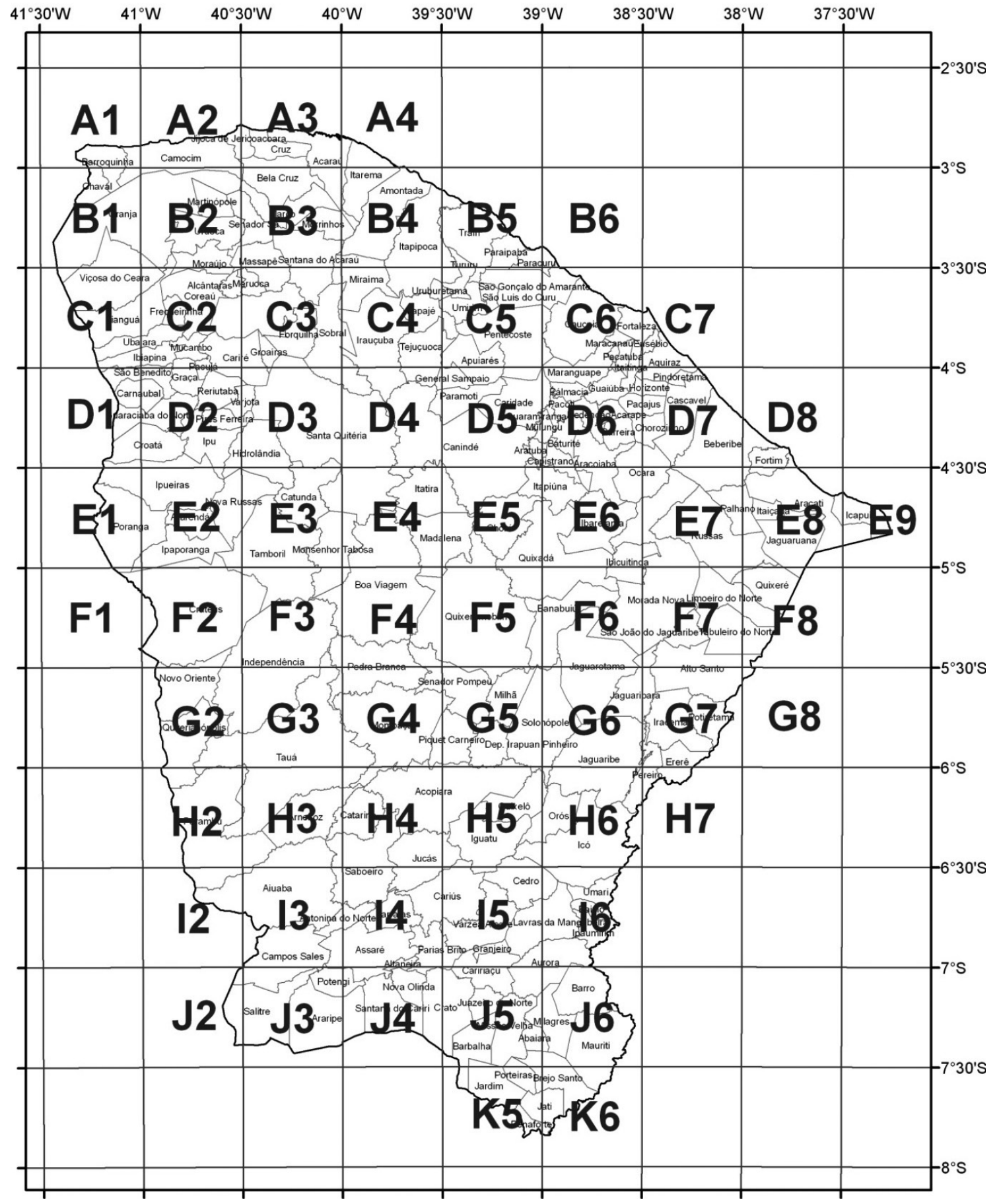

Figura 1 - Divisão política do estado do Ceará com grade de coordenadas de meio grau (A1-K6). Fonte: Menezes et al. (2013).

Figure 1 - Political division of the state of Ceará with a half degree grid (A1-K6). Credits: Menezes et al. (2013). 
da conservação do grupo para o Ceará e Brasil e também, um maior esforço de coletas para os representantes deste gênero.

\section{Tratamento taxonômico}

Tephrosia Pers., Synopsis Plantarum 2(2): 328. 1807.

Erva, subarbusto a arbusto, ereto ou rastejante. Caule cilíndrico, anguloso, glabro a pubescente. Estípulas 2. Folhas 7-multifolioladas, alternas, espiraladas; pecíolo e raque sulcados, glabros a pubescentes; folíolos simétricos, opostos, margem inteira, glabros a pubescentes na face adaxial e pubescentes na face abaxial, nervação camptódroma. Inflorescência em pseudoracemo axial ou terminal, pauciflora ou multiflora. Brácteas persistentes ou decíduas. Flores bissexuadas, hipóginas, zigomorfas, pentâmeras. Cálice campanulado, concrescido, 5-laciniado; corola papilionácea, 5 pétalas, concrescidas, amarelas, róseas, roxas ou vermelhas; androceu pseudomonadelfo, livres, exsertos, anteras bitecas, rimosas, introrsas; gineceu unicarpelar; ovário súpero, pluriovulado, pubescente; estilete glabro ou pubescente, estigma capitado ou penicelado. Fruto legume, linear, pubescente, cálice e estilete persistentes. Sementes numerosas, lisas ou rugosas, monocromadas ou marmoradas.

\section{Chave de identificação das espécies de Tephrosia ocorrentes no Ceará}

1. Arbusto ereto; folhas 29-37-folioladas, folíolos oblongos 5. Tephrosia sinapou

1'. Subarbusto decumbente; folhas 7-15-folioladas, folíolos elípticos, obovados ou oblanceolados.

2. Tubo do cálice maior que o comprimento dos lacínios.

3. Estípulas $7-14 \times 10-11 \mathrm{~mm}$; pedicelo arqueado 3. Tephrosia egregia

3'. Estípulas $2-7 \times 1-2 \mathrm{~mm}$; pedicelo reto 1. Tephrosia cinerea

2'. Tubo do cálice menor que o comprimento dos lacínios.

4. Inflorescência pauciflora (1-3 flores), 8,5-11 cm compr.; 1 botão por nó; cálice velutino ... 2. Tephrosia domingensis

4'. Inflorescência multiflora (mais de 10 flores), 4,4 cm compr., 2 botões por nó; cálice seríceo a estrigoso 4. Tephrosia purpurea

1. Tephrosia cinerea (L.) Pers., Synopsis Plantarum 2(2): 328-329. 1807. Figs. 1; 2a,b; 3a-j

Subarbusto decumbente. Caule cilíndrico, anguloso, estriado; ramo pouco difuso, estreito, indumento cinéreo-seríceo. Estípulas 2-7 × 1-2 $\mathrm{mm}$, triangulares, hirsutas, decíduas. Folhas 7-15-folioladas; pecíolo 0,2-1 cm compr., sulcado, hirsuto; raque 0,5-4,1 cm compr., sulcada, hirsuta; peciólulo 1-2 $\mathrm{mm}$ compr., hirsuto; folíolos $0,6-4 \times 0,2-1,4 \mathrm{~cm}$, elípticos a obovados, ápice arredondado, emarginado ou retuso, mucronulado, base cuneada a obtusa, face adaxial e abaxial seríceo-cinéreas, 7(-8)-10 pares de nervuras secundárias. Brácteas ca. $2 \mathrm{~mm}$ compr. Botão floral 1,3-0,4 $\times 0,4-0,2 \mathrm{~cm}$, axilar, $1-2$ por nó, seríceo. Flores 1,2-2 cm compr., axilares, solitárias; pedicelo $0,4-0,8 \mathrm{~cm}$ compr., reto, indumento hirsuto; cálice 5-7 mm compr., tubo maior que o comprimento dos lacínios, campanulado, indumento seríceo, lacínios ca. $4 \times 0,3 \mathrm{~mm}$, triangulares a estreito triangulares; corola rósea, vexilo 1,1-1,4 × 1-1,1 $\mathrm{cm}$, largo ovado, ápice emarginado, dorsalmente seríceo; ala ca. 1,1-1,4 × 0,4-0,5 cm, ovada, ápice arredondado; carena ca. $1-1,1 \times 0,4-0,5 \mathrm{~cm}$, ovada, ápice acuminado, conata, cuculada; tubo estaminal $0,7-1,4 \times 0,2-0,3 \mathrm{~cm}$, porção livre 0,3 $\mathrm{cm}$, anteras ca. $0,5 \times 0,1-0,2 \mathrm{~mm}$; ovário ca. 0,8 $\times 0,1 \mathrm{~cm}$, indumento seríceo, unilocular, 6 óvulos; estilete $1-1,5 \mathrm{~cm}$ compr., glabro, estigma ca. 0,3 $\mathrm{mm}$, capitado, ciliado. Legume 3,2-4 ×0,3-0,4 cm, linear, cartáceo, seríceo; cálice, estilete e estigma persistentes; pedicelo frutífero $0,4-0,7 \mathrm{~cm}$ compr. Sementes imaturas ca. 2,5-2,7 $\times 2 \mathrm{~mm}$, castanhas, suborbiculares, rugosas.

Material examinado: Aiuaba, Estação Ecológica de Aiuaba, 30.IV.1981, fl. e fr., P. Martins (EAC 10244). Beberibe, margem da CE-040, 27.IV.2010, fl. e fr., E.R. Silveira (EAC 47129). Caucaia, Praia de Iparana, 13.IX.2002, fl. e fr., A.S.F. Castro 1369 (EAC 32266); Fortaleza, Praia do Meireles, 2.II.1963, fr., A. Fernandes (EAC 2227). Iguatu, 29.III.1985, fr., A. Fernandes (EAC 13076). Itarema, Praia de Itarema, 19.I.1998, veg., $A$. Fernandes (EAC 26099). Lavras da Mangabeira, rodovia entre Lavras da Mangabeira e Várzea Alegre, 17.V.1985, fr., M.A. Figueiredo (EAC 13174); Novo Oriente, 10.III.2002, fl. e fr., A. Fernandes (EAC 31388; UFRN 2343). Quixadá, Estrada para Confiança, 14.VI.1975, fl., 

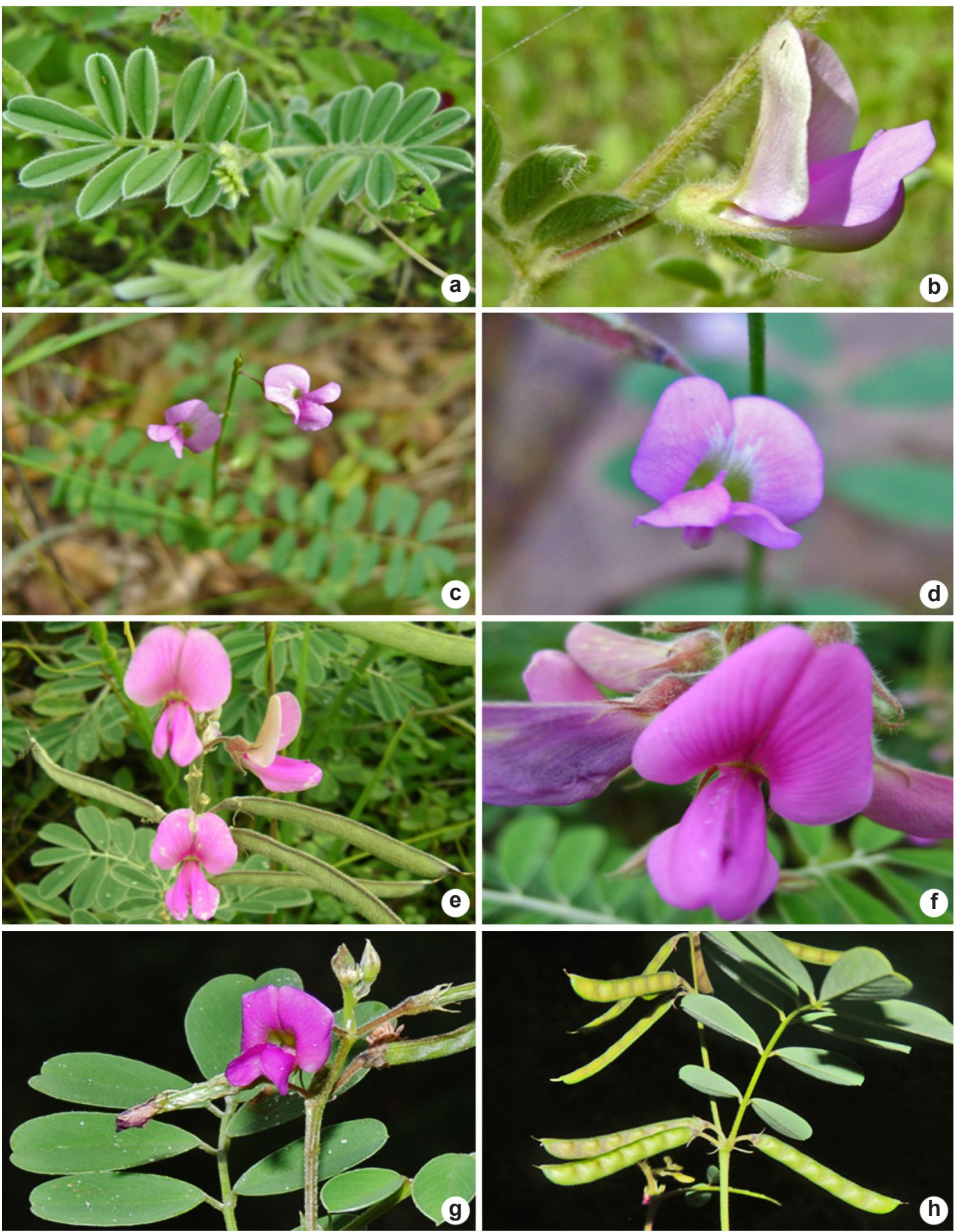

Figura 2 - Tephrosia do Ceará - a-b. T. cinerea - a. folhas; b. flor. c-d. T. domingensis - c. inflorescência; d. flor. e-f. T. egregia - e. inflorescência com flores e frutos; f. flor. g-h. T. purpurea. g. folha e flor; h. frutos. Fotos: a-h - R.T. Queiroz.

Figure 2 - Tephrosia of Ceará - a-b. T. cinerea - a. leaves; b. flower. c-d. T. domingensis - c. inflorescence; d. flower. e-f. T. egregia - e. inflorescence with flowers and fruits; f. flower. g-h. T. purpurea - g. leaf and flower; h. fruits. Credits: a-h - R.T. Queiroz. 

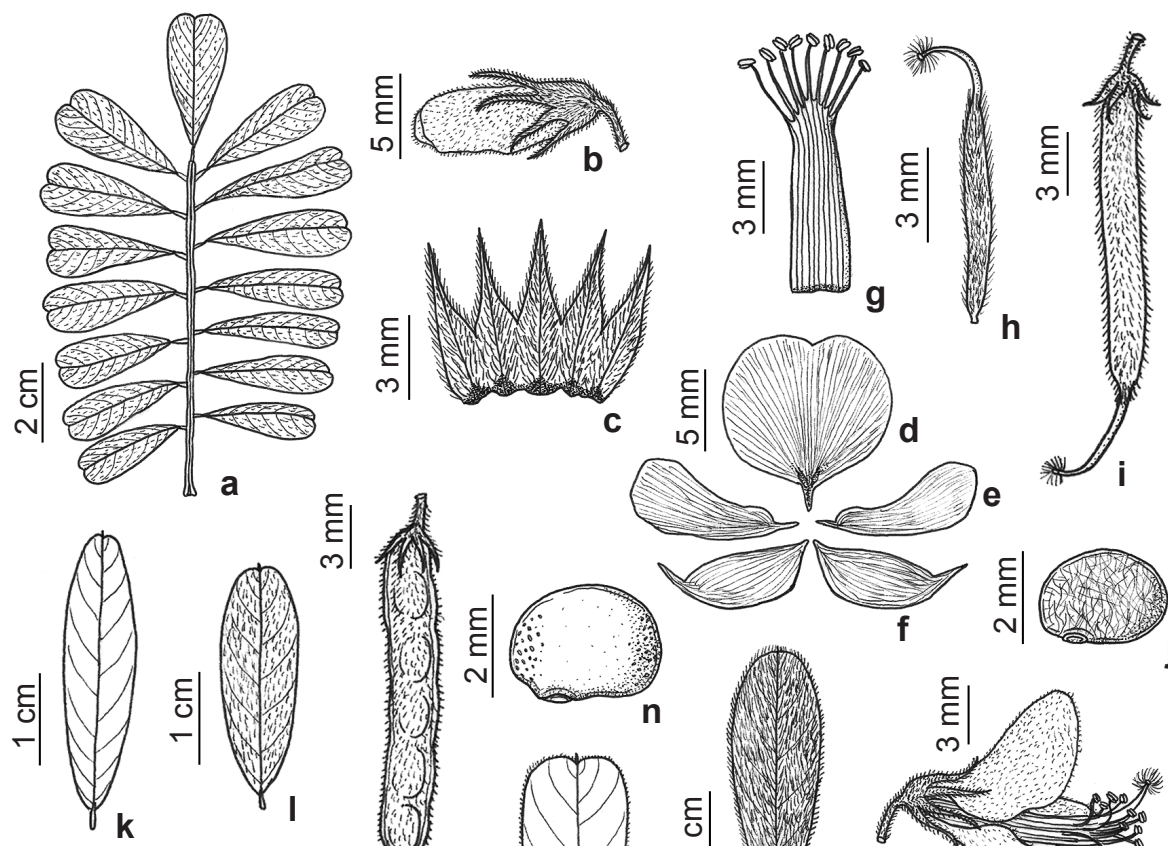

$\varepsilon$
हा
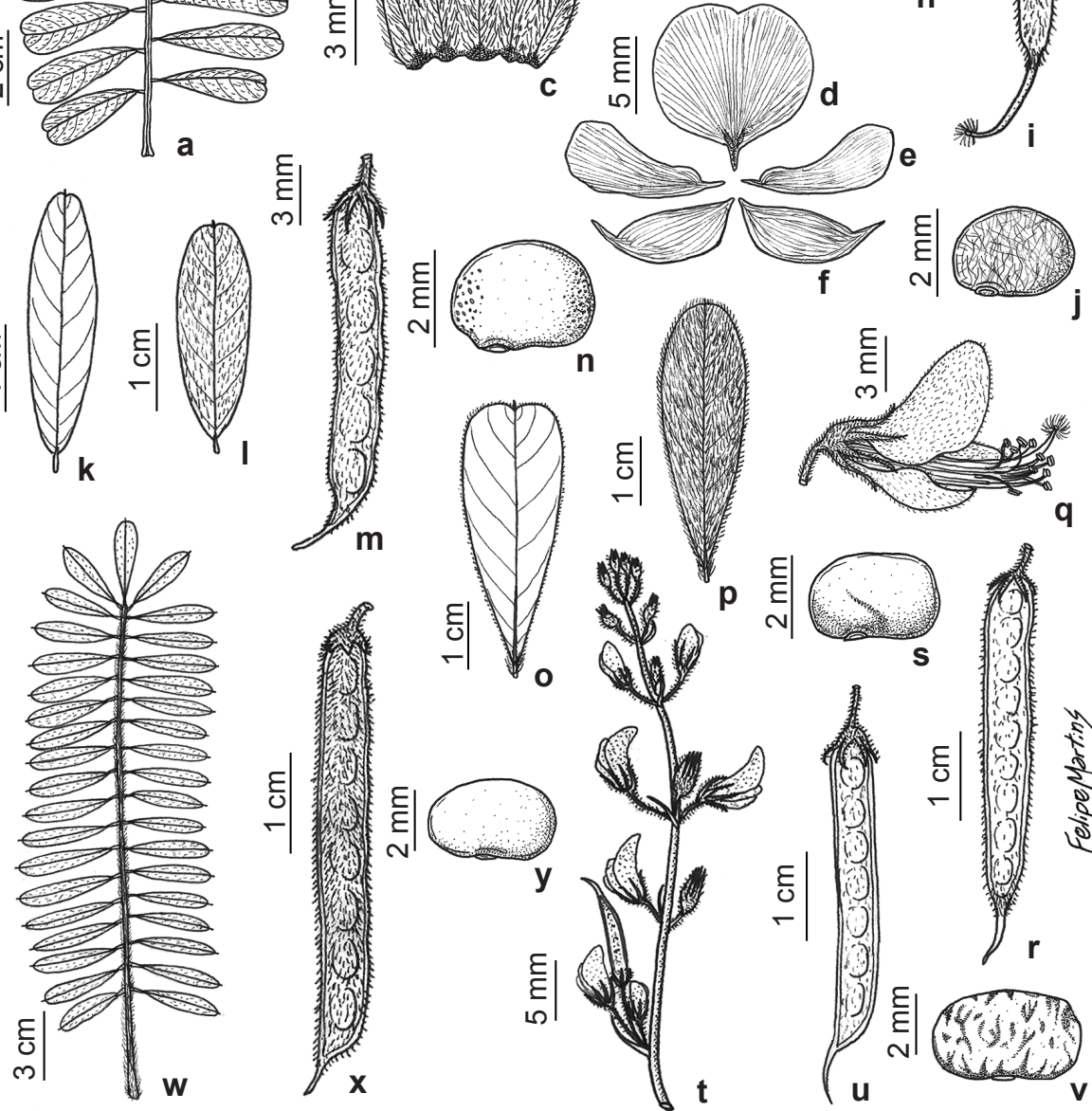

\section{j}
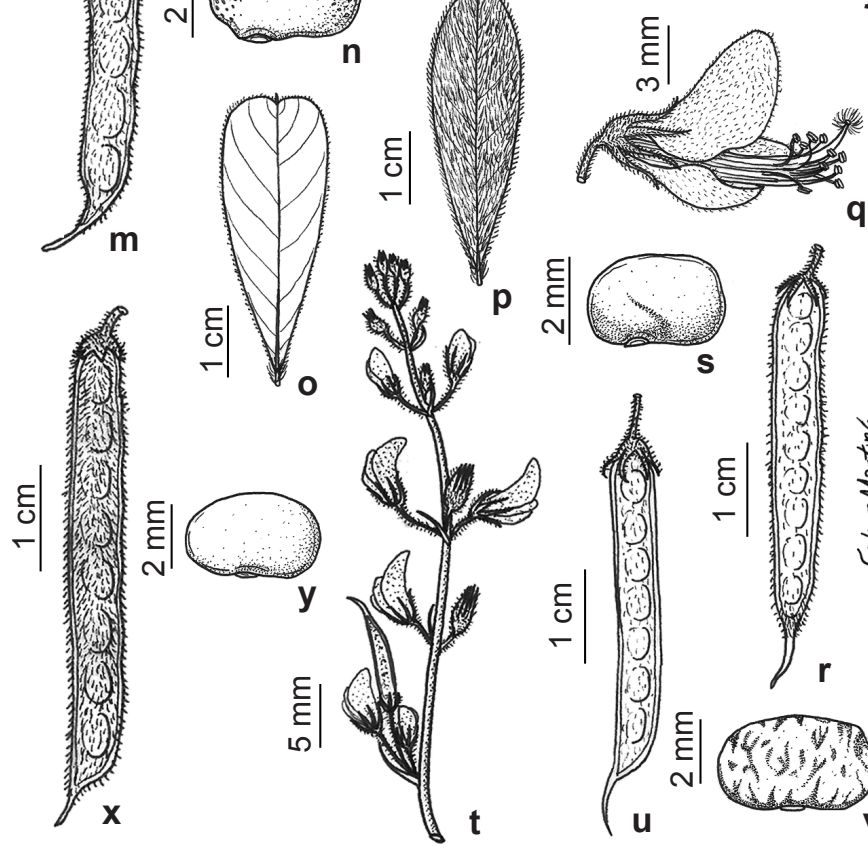

9
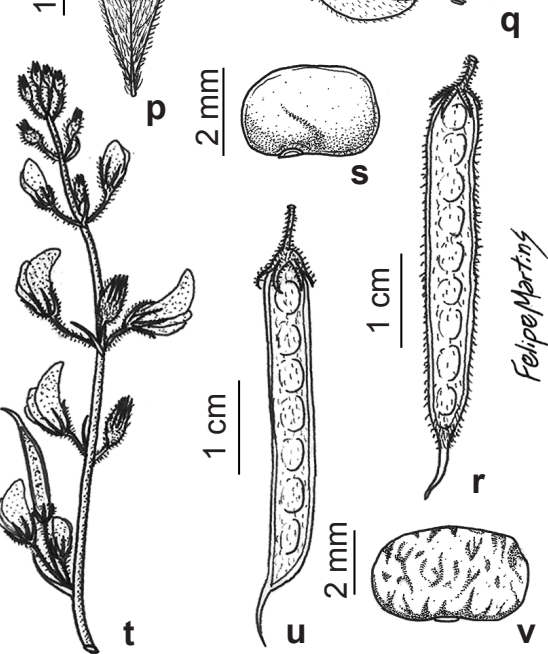

Figura 3 - Tephrosia do Ceará - a-j. T. cinerea - a. folha; b. botão; c. cálice; d. vexilo; e. alas; f. quilhas; g. tubo estaminal aberto; h. gineceu; i. legume; j. semente. k-n. T. domingensis - k. folíolo elíptico, face adaxial; 1. folíolo obovado, face abaxial; m. legume; n. semente. o-s. T. egregia - o. folíolo, face adaxial; p. folíolo, face abaxial; q. flor; r. legume; s. semente. t-v. T. purpurea - t. inflorescência com flores e frutos em desenvolvimento; u. legume; v. semente. w-y. T. sinapou - w. folha; x. fruto; y. semente (a. A. Fernandes, EAC 12348; b. A. Fernandes, EAC 31388; c. A. Fernandes, EAC 31388; d. A. Fernandes, EAC 31388; e. A. Fernandes, EAC 31388; f. A. Fernandes, EAC 31388; g. A. Fernandes, EAC 31388; h. A. Fernandes, EAC 31388; i. A.S.F. Castro 1369; j. A.S.F. Castro 1369; k-n. A. Fernandes, EAC 6557; o-s. A. Ducke, EAC 1600; t. D.S. Sampaio 24; u. E.B. Souza 11; v. E.B. Souza 11; w-y. J.N. Vasconcelos, EAC 53996).

Figure 3 - Tephrosia of Ceará - a-j. T. cinerea - a. leaf; b. bud; c. calyx; d. standard; e. claw; f. wings; g. open staminal tube; h. gynoecium; i. legume; j. seed. k-n. T. domingensis - k. elliptic leaflet, adaxial surface; 1 . obovate leaflet, abaxial surface; $\mathrm{m}$. legume; n. seed. o-s. T. egregia - o. leaflet, adaxial surface; p. leaflet, abaxial surface; q. flower; r. legume; s. seed. t-v. T. purpurea - t. inflorescence with flowers and fruits in development (D.S. Sampaio 24); u. legume; v. seed. w-y. T. sinapou - w. leaf; x. fruit; y. seed. (a. A. Fernandes, EAC 12348; b. A. Fernandes, EAC 31388; c. A. Fernandes, EAC 31388; d. A. Fernandes, EAC 31388; e. A. Fernandes, EAC 31388; f. A. Fernandes, EAC 31388; g. A. Fernandes, EAC 31388; h. A. Fernandes, EAC 31388; i. A.S.F. Castro 1369; j. A.S.F. Castro 1369; k-n. A. Fernandes, EAC 6557; o-s. A. Ducke, EAC 1600; t. D.S. Sampaio 24; u. E.B. Souza 11; v. E.B. Souza 11; w-y. J.N. Vasconcelos, EAC 53996). 
A. Fernandes (EAC 2566). Quixeré, Fazenda Mato Alto, 13.VI.1996, veg., L.W. Lima-Verde 234 (EAC 42509). Santa Quitéria, Fazenda Itataia, 29.II.1984, veg., $A$. Fernandes (EAC 12348). São Gonçalo do Amarante, mangue do rio Guaribas-Zona 24, 5.IV.2008, fl., M.F. Moro 356 (EAC 42577). Senador Pompeu, a $10 \mathrm{~km}$ da cidade na estrada para Piquet Carneiro, 18.VII.2013, veg., A.S.F. Castro 2748 (EAC 54650). Trairi, Fleixeiras, 19.VII.2001, fl., A.M.C. Arriaga (EAC 30839). Várzea Alegre, Sítio Logradouro, 10.VI.1982, veg., M.A. Figueiredo (EAC 11784).

Tephrosia cinerea distingue-se das demais espécies do gênero por apresentar ramos, folhas e frutos recobertos por tricomas de coloração acinzentada (cinérea). Segundo Queiroz (2012), esta espécie apresenta ampla distribuição na América Central e do Sul, e também ocorre nos Estados Unidos. No Brasil pode ser encontrada em quase todas as regiões fitogeográficas, como Amazônia, Caatinga, Cerrado e Pantanal (BFG 2015; Queiroz 2017). No Ceará ocorre em ambientes secos e com influência antrópica, em vegetação de savana estépica (caatinga arbustiva), floresta estacional decidual (mata seca) e floresta estacional semidecidual de terras baixas (tabuleiro costeiro). Tephrosia cinerea não está ameaçada de extinção, devido a sua ampla distribuição $\left(\mathrm{EOO}=1.318 .403,5 \mathrm{~km}^{2}\right)$ e presença em unidades de conservação (UC) (CNCFlora 2016). No Ceará, a espécie é amplamente distribuída ( $>15$ municípios), nas quadrículas A4, B5, C6, D3, D7, E6, F5, G5, H5, I3 e I7 (Fig. 1). Tephrosia cinerea ocorre em duas unidades de conservação no Ceará, a Estação Ecológica de Aiuaba e Área de Proteção Ambiental do Pecém. Coletada com flores e frutos de fevereiro a setembro

\section{Tephrosia domingensis (Willd.) Pers., Synopsis} Plantarum 2(2): 330. $1807 . \quad$ Figs. 1; 2c,d; 3k-n Subarbusto decumbente. Caule cilíndrico, anguloso, estriado; ramo bem difuso, laxo, indumento esparso seríceo. Estípulas 3-8 $\times$ 0,4-0,6 $\mathrm{mm}$, triangulares, esparso seríceas, decíduas. Folhas 7-15-folioladas; pecíolo 1,9-3,2 cm compr., sulcado, seríceo; raque 1,8-5,2 cm compr., sulcada, serícea; peciólulo ca. $1 \mathrm{~mm}$ compr., seríceo; folíolos $0,5-2,4 \times 0,1-0,6 \mathrm{~cm}$, elípticos a obovados, ápice obtuso, agudo ou, menos frequente, emarginado, mucronulado, base aguda, face adaxial glabra, abaxial serícea, $8-15$ pares de nervuras secundárias. Pseudoracemo axial ou terminal, laxo, inflorescência com eixo principal $8,5-11 \mathrm{~cm}$ compr., pauciflora, 1-3 flores, estriada, serícea. Brácteas 3-4 mm compr.
Botão floral ca. $0,2-0,3 \mathrm{~cm}$ compr., axilar, 1 por nó, seríceo. Flores 0,4-0,6 cm compr., axilares; pedicelo $0,1-0,4 \mathrm{~cm}$ compr., reto, indumento seríceo; cálice 1-1,5 mm compr., tubo menor que o comprimento dos lacínios, campanulado, indumento seríceo, lacínios ca. $2 \times 0,5-0,8 \mathrm{~mm}$, triangulares a estreito triangulares; corola rósea, vexilo $0,4-0,5 \times 0,5-0,7 \mathrm{~cm}$, largo ovado, ápice emarginado, dorsalmente seríceo; ala ca. 0,4 × 0,3 $\mathrm{cm}$, ovada, ápice arredondado; carena ca. 0,3 × 0,2 $\mathrm{cm}$, ovada, ápice acuminado, conata, cuculada; tubo estaminal $0,4-0,5 \times 0,2-0,3 \mathrm{~cm}$, porção livre 0,2 $\mathrm{cm}$, anteras ca. 0,5 × 0,1 mm; ovário ca. 0,2 $\times 0,1$ $\mathrm{cm}$, indumento seríceo, 2-7 óvulos; estilete ca. 0,3 cm compr., glabro, estigma ca. $0,3 \mathrm{~mm}$, capitado, penicilado. Legume 3,1-4 × 0,3-0,5 cm, linear, cartáceo, seríceo; cálice e estilete persistentes; pedicelo frutífero $0,3-0,4 \mathrm{~cm}$ compr. Sementes ca. $2 \times 1,8 \mathrm{~mm}$, castanhas, reniformes com perfurações irregulares nas laterais.

Material examinado: Guaraciaba do Norte, Serra da Ibiapaba, 15.VI.1979, fr., A. Fernandes (EAC 6557).

Material adicional examinado: BRASIL. PIAUÍ: Ribeiro Gonçalves, Estação Ecológica de Uruçuí-UNA, 15.IV.1981, fl., A. Fernandes (EAC 10002).

Tephrosia domingensis distingue-se das demais espécies encontradas no Ceará por possuir apenas hábito subarbustivo decumbente, ramos com indumento esparso seríceo e folhas com 8-15 pares de nervuras secundárias, inflorescência pauciflora. Segundo Queiroz (2012), T. domingensis apresenta ampla distribuição na América do Sul. No Brasil pode ser encontrada no Cerrado e Pantanal (Queiroz 2017). Em território cearense é a espécie com distribuição mais restrita e, ao contrário das demais espécies, se desenvolve apenas em ambiente úmido de floresta ombrófila densa (mata úmida). Não foram encontradas informações sobre a conservação da espécie na literatura. No Ceará ocorre apenas no município de Guaraciaba do Norte (D2), sendo considerada restrita e não há registro de T. domingensis em unidades de conservação do estado. Coletada com flores em abril e frutos em junho.

3. Tephrosia egregia Sandwith, Bulletin of Miscellaneous Information Kew 1927(6): 249-250. 1927.

Figs. 1 ; 2e,f; 3o-s

Subarbusto decumbente. Caule cilíndrico, anguloso, estriado; ramo difuso, laxo, glabro. Estípulas 7-14 × 10-11 mm, estreito triangulares, seríceas, persistentes. Folhas 9-15-folioladas; pecíolo $0,3-0,6 \mathrm{~cm}$ compr., sulcado, hirsuto; raque 
3,7-4,7 cm compr., sulcada, serícea a hirsuta; peciólulo 1-2 mm compr., seríceo a hirsuto; folíolos 0,6-4,9 × 0,4-1,6 cm, elípticos, obovados a oblanceolados, ápice agudo, arredondado, emarginado ou retuso, mucronulado, base cuneada a obtusa, face adaxial glabra a serícea, abaxial serícea, 7-12(-15) pares de nervuras secundárias. Pseudorracemo axilar ou terminal, laxo, inflorescência com eixo principal 18,5-27,4 $\mathrm{cm}$ compr., multiflora, estriada, serícea. Brácteas $3-10 \times 1-4 \mathrm{~mm}$ compr. Botão floral 0,9-1,1 $\times 0,3-0,4 \mathrm{~cm}$, axilar, 1 por nó, seríceo. Flores $1,2-1,5 \mathrm{~cm}$ compr., axilares; pedicelo $0,5-0,9 \mathrm{~cm}$ compr., arqueado, indumento hirsuto; cálice ca. $0,8 \mathrm{~cm}$ compr.; tubo maior que o comprimento dos lacínios, campanulado, indumento seríceo, lacínios ca. $5 \times 1 \mathrm{~mm}$, triangulares; corola rósea, vexilo $1-1,3 \times 1-1,1 \mathrm{~cm}$, largo ovado, ápice retuso, dorsalmente seríceo; ala ca. 0,9 × 0,7 cm, ovada, ápice arredondado; carena ca. 1-1,1 × 0,4-0,5 $\mathrm{cm}$, ovada, ápice agudo, conata, cuculada; tubo estaminal 1,2-1,3 cm compr., porção livre ca. 0,3 $\mathrm{cm}$, anteras ca. $0,5 \times 0,4 \mathrm{~mm}$; ovário ca. $0,8 \times$ $0,6 \mathrm{~cm}$, indumento seríceo, unilocular, 8 óvulos; estilete ca. $0,5 \mathrm{~cm}$ compr., seríceo, estigma ca. $0,2 \mathrm{~mm}$ diâm., capitado, penicilado. Legume 3,7-5,4 × 0,3-0,5 cm, linear, coriáceo, seríceo; cálice persistente; pedicelo frutífero $0,5-0,9 \mathrm{~cm}$ compr. Sementes 3,2-4 × 2,1-2,7 mm, amareladas, retangulares.

Material examinado: Caucaia, Praia da Tabuba, 25.IX.2005, veg., V.B. Marques s.n. (EAC 38162). Fortaleza, Antônio Bezerra, 26.XI.1954, veg., P. Bezerra (EAC 1029). Icapuí, Ponta Grossa, 15.IX.2000, veg., Montenegro 35 (EAC 30480). Itapipoca, Praia do Pirata, 14.IV.2001, fl., E. Trigueiro (EAC 30597). Itarema, Praia de Itarema, 15.I.1998, fl., A. Fernandes (EAC 26101). Quixeré, Fazenda Mato Alto, 13.VI.1996, fl., E.L. PaulaZárate 234 (EAC 39259; MOSS 8063). Santa Quitéria, Fazenda Itataia, 23.IV.2012, fl. e fr., Paula-Souza 10781 (EAC 54362; ESA 124444). Trairi, Fleixeiras, 2.V.1998, veg., A. Fernandes (EAC 26343).

Tephrosia egregia caracteriza-se pelos ramos com indumento seríceo a hirsuto, folhas 9-15-folioladas, presença de 7-12(-15) pares de nervuras secundárias e estigma capitado penicilado. A espécie é endêmica do Brasil e ocorre nos domínios fitogeográficos, Caatinga e Mata Atlântica (Queiroz 2017). No Ceará foi encontrada em oito municípios em áreas de dunas, em vegetação de restinga e caatinga. Não foram encontradas informações sobre a conservação da espécie na literatura. No Ceará, Tephrosia egregia apresenta distribuição moderada (oito municípios), nas quadrículas A4, B4, B5, C6, D3, E9 e F5. A espécie consta em uma unidade de conservação, a Área de Proteção Ambiental de Redonda. Coletada com flores entre janeiro e junho e frutos em abril.

4. Tephrosia purpurea (L.) Pers., Synopsis Plantarum 2(2): 329. $1807 . \quad$ Figs. 1; 2g,h; 3t-v Subarbusto decumbente. Caule cilíndrico, anguloso, estriado; ramo bem difuso, glabro. Estípulas 1-2 × 0,5-0,8 mm, triangulares, seríceas, persistentes; Folhas 9-15-folioladas; pecíolo 0,4 $2,7 \mathrm{~cm}$ compr., sulcado, seríceo; raque 1,6-4,6 cm compr., sulcada, serícea a hirsuta; peciólulo 1-1,5 $\mathrm{mm}$ compr., hirsuto; folíolos $0,9-2,4 \times 0,2-0,1$ $\mathrm{cm}$, obovados a oblanceolados, ápice retuso a emarginado, mucronulado, base cuneada, face adaxial glabra e abaxial serícea, 8 pares de nervuras secundárias. Pseudorracemo axilar, inflorescência com eixo principal $4,4 \mathrm{~cm}$ compr, multiflora (10 flores ou mais), estriada, serícea. Brácteas 1-2 $\mathrm{mm}$ compr. Botão floral $0,3-0,8 \times 0,1-0,3 \mathrm{~cm}$, axilar, 2 por nó, seríceo. Flores $0,6-1 \mathrm{~cm}$ compr., axilares; pedicelo $0,3-0,8 \mathrm{~cm}$ compr., indumento hirsuto; cálice ca. $0,5 \mathrm{~mm}$ compr.; tubo menor que o comprimento dos lacínios, campanulado, indumento seríceo a estrigoso, lacínios $0,5-0,8 \mathrm{~mm}$ compr., triangulares a estreito triangulares; corola amarela, rósea a roxa, vexilo ca. $0,7 \mathrm{~cm}$ compr., largo obovado, ápice retuso, dorsalmente seríceo; ala ca. 0,7 ×0,2 cm, ovada, ápice arredondado; carena ca. 0,6 $\times 0,3 \mathrm{~cm}$, ovada, ápice acuminado, conata, cuculada; tubo estaminal ca. $1 \times 0,1 \mathrm{~cm}$, porção livre ca. $0,2 \mathrm{~cm}$ compr., anteras $0,3 \times$ $0,2 \mathrm{~mm}$; ovário $0,8 \times 0,1 \mathrm{~cm}$ compr., indumento seríceo, unilocular, 5-7 óvulos; estilete $1,3 \mathrm{~cm}$, seríceo, estigma ca. $0,2 \mathrm{~mm}$ diâm., capitado, penicilado. Legume 3,4-3,7 × 0,3-0,4 cm, linear, cartáceo, seríceo, cálice persistente; pedicelo frutífero 0,3-0,7 cm compr. Sementes 3,5-4 $\times$ 1,5-2 $\mathrm{mm}$, vermelhas, variegadas, reniformes.

Material selecionado: Acaraú, Lagoa de Jijoca, 5.IV.1984, veg., A. Fernandes (EAC 12429). Aiuaba, 21.III.1991, veg., M.A. Figueiredo 43 (EAC 16898; MOSS 2985). Aracati, Fazenda Belém, 2.VI.2014, veg., M.I.B. Loiola 2292 (EAC 56084). Canindé, Margens da estrada de Canindé, 18.IX.1985, fl., E. Nunes (EAC 13582; MBM 105945). Cascavel, 18.I.1975, fl., $A$. Fernandes s.n. (EAC 2532). Caucaia, 8.VI.2002, fl., M.R. Andrade (EAC 31617). Coreaú, Campanário, 9.I.1985, fl. e fr., A. Fernandes (EAC 12960). Crateús, 10.V.1996, veg., F.S. Cavalcanti (EAC 23827). Granja, Entrada da Vereda do Tomás, 21.V.2015, veg., E.B. Souza 3500 (EAC 58612). Icapuí, APA de Redonda, 29.IV.2000, fl., R.S. Oliveira 16 (EAC 30491). Iguatu, 
Campanário, 9.I.1985, fl. e fr., A. Fernandes (EAC 12960). Jaguaribe, 16.V.1985, veg., A. Fernandes (EAC 23827). Paraipaba, Lagoinha, 8.VI.2002, veg., D.V. Azevedo 3 (EAC 32913). Pentecoste, 26.IV.1992, fl., M. Andrade (EAC 18530). Quixadá, Estrada entre Quixadá e Icó, 19.III.1998, fl. e fr., A. Fernandes (EAC 26163). Santa Quitéria, 25.II.1995, veg., F.S. Cavalcanti (EAC 21937). São Gonçalo do Amarante, Pecém, 12.VII.1999, fl. e fr., D.S. Sampaio 24 (EAC 28219). Senador Pompeu, 28.VII.1991, fl. e fr., E.B. Souza 11 (EAC 18373; HUEFS 138426). Tabuleiro do Norte, 29.XI.2013, veg., A.E.S. Ferreira 88 (EAC 56411). Trairi, Fleixeiras, 2.V.1998, veg., A. Fernandes (EAC 26344).

Tephrosia purpurea é considerada polimórfica, o que dificulta às vezes a sua identificação (Chang et al. 1997; Queiroz 2009). Os espécimes de T. purpurea analisados caracterizam-se por ramos com indumento seríceo, folhas 9-15-folioladas e folíolos com 8 pares de nervuras secundárias. A espécie apresenta ampla distribuição, sendo nativa do sul da Ásia, da África, Austrália e introduzida nas Américas (Queiroz 2009; Efloras 2016). No Brasil ocorre nos domínios fitogeográficos, Caatinga e Mata Atlântica especialmente em áreas antropizadas (Queiroz 2017). Em território cearense, Tephrosia purpurea ocorre preferencialmente em ambientes secos e fortemente antropizados, em floresta estacional decidual (mata seca), floresta estacional semidecidual de terras baixas (tabuleiros costeiros), vegetação com influência marinha (restinga) e savana estépica (caatinga). Segundo Queiroz (2012), a espécie é ruderal, e, facilmente encontrada em grandes populações em beiras de estrada, terrenos baldios e ambientes abertos de solos arenosos. Não foram encontradas informações sobre a conservação da espécie na literatura. No Ceará apresenta ampla distribuição, ocorrendo em 20 municípios, nas quadrículas A3, B2, B5, C2, C5, C6, D3, D5, E6, E7, E8, E9, F2, F8, G5, G6, H5 e I3. Tephrosia purpurea está presente em duas unidades de conservação do Ceará, o Parque Nacional de Jericoacoara e a Área de Proteção Ambiental de Redonda. Encontrada com flores nos meses de janeiro a setembro e com frutos entre janeiro e julho. Conhecida popularmente como "cipó", "iguaçu" ou "caça-poeira".

5. Tephrosia sinapou (Buc'hoz) A. Chev. Comptes Rendus Hebdomadaires des Séances de l'Académie des Sciences 180: 1522. $1925 . \quad$ Fig. 1; 3w-y

Arbusto ereto. Caule cilíndrico, sulcado, não estriado; ramo muito difuso, laxo, indumento estrigoso. Estípulas ca. 0,9-1,1 × $0,1 \mathrm{~cm}$, estreito triangulares, seríceas, decíduas. Folhas 29-37-folioladas; pecíolo 1,8-3 cm compr., sulcado, tomentoso; raque 8,5-14 cm compr., sulcada, tomentosa; peciólulo 1-4 mm compr., tomentoso; folíolos 2,4-4,5 × 0,3-0,7 cm, oblongos, ápice mucronado, base cuneada, face adaxial serícea e abaxial densamente serícea, 7-15 pares de nervuras secundárias. Pseudorracemo axilar ou terminal, laxo, inflorescência com eixo principal ca. 8,2 cm compr., pauciflora ou multiflora, 3-9 flores, sulcada, serícea. Brácteas ca. $5 \mathrm{~mm}$ compr. Botão floral ca. 0,6-0,7 ×0,4 cm, axilar, 3-6 por nó, seríceo. Flores 1,4-2 cm compr., axilares; pedicelo $0,3-0,6 \mathrm{~cm}$ compr., reto, indumento hirsuto; cálice 4-5 mm compr., tubo maior ou igual ao comprimento dos lacínios, campanulado, indumento seríceo a tomentoso, lacínios ca. 1-4× 1-2 mm, oblongos a obovados; corola vermelha, vexilo $1,1-1,5 \times 1-1,6 \mathrm{~cm}$, orbicular a largo obovado, ápice retuso, dorsalmente tomentoso; ala 1,1-1,3 × 0,4-0,5 cm, estreito-elíptica, ápice arredondado; carena ca. 1-1,2 ×0,4-0,5 cm, ovada, ápice agudo a arredondado, conata, cuculada; tubo estaminal $1-1,2 \times 0,3-0,4 \mathrm{~cm}$, porção livre $0,2-0,5$ cm compr., anteras ca. $0,5 \times 0,2 \mathrm{~mm}$; ovário ca. $1-1,4 \times 0,1-0,2 \mathrm{~cm}$, indumento tomentoso; estilete 0,5-0,7 cm compr., glabro, estigma ca. 0,3 mm, recurvado. Legume 3,8-5,4 × 0,2-0,5 cm, linear, coriáceo, pubescente, cálice persistente; pedicelo frutífero ca. $4 \mathrm{~mm}$ compr. Semente ca. $4 \times 2 \mathrm{~mm}$, castanhas, reniformes.

Material examinado: Guaraciaba do Norte, 1.VII.2002, bot. e fr., A.M. Andrade (EAC 32139). Tianguá, 4.VIII.2015, fr., J.N. Vasconcelos (EAC 53996).

Material adicional examinado: BRASIL. BAHIA: Formosa do Rio Preto, 15.V.1982, fl e fr., A. Fernandes (EAC 11316).

Caracteriza-se por suas folhas 29-37-folioladas, folíolos, maiores que os das demais espécies, 2,4-4,5 × 0,3-0,7 cm, oblongos. Segundo Wood (1949), Tephosia sinapou e T. nitens são os únicos membros do grupo barbistilíco, considerado natural e quase restrito a América do Norte, com ocorrência América do Sul, sendo nativa da região equatorial amazônica (Queiroz 2009). Conforme Wood (1949), o número elevado de folíolos e flores nas espécies de Tephrosia com estiletes barbelados representa uma condição intermediária no gênero. No Brasil ocorre nos domínios fitogeográficos, Amazônia e Mata Atlântica (Queiroz 2017). Em território cearense, Tephrosia sinapou apresenta apenas dois registros nas quadrículas C1 e D1, em ambientes úmidos e caracterizados por vegetação de floresta ombrófila 
densa (mata úmida). Constitui uma nova ocorrência para o estado. Não foram encontradas informações sobre a conservação da espécie e não há registros de ocorrência para unidades de conservação no Ceará. Coletada com flores em maio e frutos nos meses de julho e agosto.

Segundo Queiroz (2009), esta espécie já foi muito utilizada pelos índios para captura de peixes. Tephrosia sinapou também é considerada uma espécie que apresenta compostos com ação antiinflamatória e antioxidante (Martinez et al. 2012).

\section{Agradecimentos}

À CAPES pela bolsa concedida à primeira autora; a Felipe Martins Guedes pela elaboração das ilustrações; aos projetos INCT - Herbário Virtual da Flora e Fungos do Brasil (Processo 573.883/2008-4); Rede Integrada em Taxonomia de Plantas e Fungos - SISBIOTA BRASIL (Processo $\mathrm{N}^{\circ}$ 563.342/2010-2) pelo apoio nas coletas; Maria Iracema Bezerra Loiola agradece ao CNPq pela bolsa de produtividade concedida.

\section{Referências}

Baker JG (1871) Leguminosae, Faboideae. In: Oliver D (ed.) Flora of tropical Africa. Vol. 2. Reeve \& Co., London. Pp. 110-114.

Baker JG (1876) Leguminosae, Faboideae. In: Hooker JD (ed.) Flora of British India. Vol. 1. Reeve \& Co., London. Pp. 209-214.

Bentham G (1862) Leguminosae I. In: Martius CFP von, Endlicher S \& Urban I (eds.) Flora brasiliensis. Typografia Regia, Munchen, Wien, Leipzig. Vol. 15 , pp. 45-49.

Bentham G (1864) Leguminosae, Tephrosia. In: Bentham G \& Mueller F (eds.) Flora australiensis: a description of the plants of the Australian territory. Vol. 2. Reeve \& Co., London. Pp. 202-211.

BFG - The Brazil Flora Group (2015) Growing knowledge: an overview of seed plant diversity in Brazil. Rodriguésia 66: 1085-1113.

Bosman MTM \& Haas AJP (1983) A revision of the genus Tephrosia (Leguminosae-Papilionoideae) in Malásia. Blumea 28: 445-488.

Brummitt RK (1980) Reconsideration of the genera Ptycholobium, Caulocarpus, Lupinophyllum and Requienia in relation to Tephrosia. Kew Bulletin 35: 459-473.

CNC Flora (2018) Tephrosia sessiliflora (Poir.) Hassl. Jardim Botânico do Rio de Janeiro. Disponível em <http://cncflora.jbrj.gov.br/portal/pt-br/profile/ Tephrosia sessiliflora $>$. Acesso em 12 outubro 2018.

Chang LC, Gerhauser BC, Sang L, Farnsworth NR, Pezzuto JM \& Kinghorn AD (1997) Activity-guided isolation of constituents of T. purpurea with the potential to induce the phase II enzyme, quinone reductase. Journal of Natural Products 60: 869-873.

De Candolle AP (1825) Tephrosia. In: De Candolle AP (ed.) Prodromus systematis naturalis regni vegetabilis. Vol. 2. Paris. Pp. 248-256.

eFloras-W3Tropicos (2016) Tephrosia. In: Flora of Pakistan. Missouri Botanical Garden. Disponível em $<$ http://www.efloras.org/florataxon.aspx?flora $\mathrm{id}=5 \&$ taxon_id=132453>. Acesso em 3 dezembro 2016.

Geesink R (1984) Scala millettiearum. A survey of the genera of the tribe Millettieae (Leguminosae, Papilionoideae). E.J. Brill/Leiden University Press, Leiden. 131p.

Gillett JB (1958) Notes on Tephrosia in tropical Africa. Kew Bulletin 13: 111-132.

Hickey LJ (1973) Classification of the architecture of dicotyledonous leaves. American Journal of Botany 60: 17-33.

Hu JM, Lavin M, Wojciechowski MF \& Sanderson MJ (2002) Phylogenetic analysis of nuclear ribosomal ITS/5.8 S sequences in the tribe Millettieae (Fabaceae): Poecilanthe-Cyclolobium, the core Millettieae, and the Callerya group. Systematic Botany 27: 722-733.

IBGE - Instituto Brasileiro de Geografia e Estatística (2012) Manual técnico da vegetação brasileira. $2^{\text {a }}$ ed. Disponível em <ftp://geoftp.ibge.gov.br/ documentos/recursos naturais/manuais tecnicos/ manual_tecnico_vegetacao_brasileira.pdf $>$. Acesso em 16 novembro 2016.

IPNI - The International Plant Names Index (2016) The International Plant Names Index. Disponível em $<$ http://www.ipni.org > . Acesso em 22 novembro 2016.

Lawrence GHM (1951) Taxonomia das plantas vasculares. Fundação Calouste Gulbenkian, Lisboa. $550 \mathrm{p}$.

Martinez RM, Zarpelon AC \& Zimermann VVM (2012) Tephrosia sinapou extract reduces inflammatory leukocyte recruitment in mice: effect on oxidative stress, nitric oxide and cytokine production. Revista Brasileira de Farmacognosia 22: 587-597.

Menezes MOT, Taylor NP \& Loiola MIB (2013) Flora do Ceará, Brasil: Cactaceae. Rodriguésia 64: 757-774.

Persoon CH (1807) Tephrosia. In: Persoon CH (ed.) Synopsis plantarum, seu Enchiridium botanicum 2: 328-330.

Queiroz LP (2009) Leguminosas da Caatinga. Universidade Estadual de Feira de Santana, Feira de Santana. 469p.

Queiroz RT (2012) Revisão taxonômica das espécies do gênero Tephrosia Pers. (Leguminosae, Papilionoideae, Millettieae) ocorrentes na América do Sul. Tese de Doutorado. Universidade Estadual de Campinas, Campinas. 317p. 
Queiroz RT (2017) Tephrosia. In: Flora do Brasil (2020 em construção) Jardim Botânico do Rio de Janeiro. Disponível em <http://floradobrasil.jbrj.gov.br/ reflora/floradobrasil/FB23204>. Acesso em 22 agosto 2017.

Queiroz RT, Saleh EOL \& Tozzi AMGA (2016) Millettieae - Tephrosia. In: Wanderley MGL, Shepherd GJ, Melhem TS, Giulietti AM \& Martins SE (eds.) Flora fanerogâmica do estado de São Paulo. Instituto de Botânica, São Paulo. Vol. 8, pp. 280-285.

Radford AE, Dickson WC, Massey JR \& Bell CR (1974) Vascular plant systematics. Harper \& Row, New York. 891p.

Robinson BL (1899) Revision of the North American species of Tephrosia. Botanical Gazette 28: 193202.
São-Mateus WMB, Cardoso D, Jardim JG \& Queiroz LP (2013) Papilionoideae (Leguminosae) na Mata Atlântica do Rio Grande do Norte, Brasil. Biota Neotropica 13: 315-362.

Schrire BD (1987) A synopsis of Tephrosia subgenus Barbistyla (Fabaceae) in southern Africa. Bothalia 17: 7-15.

Schrire BD (2005) Tribe Millettieae. In: Lewis G, Schrire B, Mackinder B \& Lock M (eds.) Legumes of the world. Royal Botanic Gardens, Kew. Pp. 367-387.

Thiers B [continuously updated] Index herbariorum: a global directory of public herbaria and associated staff. New York Botanical Garden's Virtual Herbarium. Disponível em $<$ http://sweetgum.nybg. org/science/ih/>. Acesso em 28 novembro 2016.

Wood CE (1949) The American barbistyled species of Tephrosia (Leguminosae). Rhodora 51: 249-380.

\section{Lista de exsicatas}

Almeida L EAC (2297) (3). Amado R EAC (28184) (1). Andrade Neto M EAC (21766), (34815), (47223) (4). Arriaga AMC EAC (55945) (3), EAC (59019) (1). Barros MM EAC (5402) (3). Castro ASF EAC (49041) (3). Cavalcanti FS EAC (39447) (3). Ducke A EAC (1600) (3). Fernandes A EAC 6557 (2), EAC 10002 (2), EAC 11316 (5), 12512 (3), EAC (2000) (3), EAC (2232) (3), EAC (5962) (3), EAC (12679) (3), EAC (17141) (1), EAC (26320) (1). Ferreira AES EAC (56397) (3). Figueireido MA (HUEFS 138430). Granjeiro TB EAC (32637) (3). Loiola MIB EAC (58785) (4). Matias LQ EAC (29007); HUEFS (138412) (3). Menezes MOT EAC (44366) (4). Montenegro. EAC (30480) (3). Paula-Souza J EAC (54350) (3). Paula-Zárate EL EAC (39259) (3). Soares RP EAC (28816) (4). Trigueiro E EAC (30601) (3). Vieira AV EAC (33750) (4). 